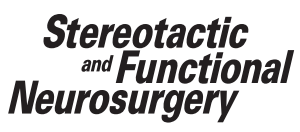

Stereotactic

Neurosurgery
Stereotact Funct Neurosurg 2011;89:131-140

DOI: $\underline{10.1159 / 000324906}$
Received: July 14, 2010

Accepted after revision: February 7, 2011 Published online: April 13, 2011

\title{
MRI-Related Heating near Deep Brain Stimulation Electrodes: More Data Are Needed
}

\author{
Akshay A. Gupte $^{\mathrm{a}, \mathrm{c}}$ Devashish Shrivastava ${ }^{\mathrm{b}}$ Maggie A. Spaniol ${ }^{\mathrm{a}}$ Aviva Abosch $^{\mathrm{a}}$ \\ a Department of Neurosurgery, University of Minnesota Medical School, and ${ }^{b}$ Center for Magnetic Resonance \\ Research and 'Division of Epidemiology and Community Health, School of Public Health, University of Minnesota, \\ Minneapolis, Minn., USA
}

\section{Key Words}

Deep brain stimulation - Magnetic resonance imaging • Parkinson's disease $\cdot$ Radiofrequency heating $\cdot$ Specific absorption rate

\begin{abstract}
Magnetic resonance imaging (MRI) of patients with implanted deep brain stimulation (DBS) devices poses a challenge for healthcare providers. As a consequence of safety concerns about magnetic field interactions with the device, induced electrical currents and thermal damage due to radiofrequency heating, a number of stringent guidelines have been proposed by the device manufacturer. Very few detailed investigations of these safety issues have been published to date, and the stringent manufacturer guidelines have gone unchallenged, leading some hospitals and imaging centers around the world to ban or restrict the use of MRI in DBS patients. The purpose of this review is to stimulate research towards defining appropriate guidelines for the use of MRI in patients with DBS. Additionally, this review is intended to help healthcare providers and researchers make sound clinical judgments about the use of MRI in the setting of implanted DBS devices.

Copyright $\odot 2011$ S. Karger AG, Basel
\end{abstract}

\section{Background}

Deep brain stimulation (DBS) has proven to be a safe and effective treatment for movement disorders, including Parkinson's disease, essential tremor and dystonia [1, 2]. The US Food and Drug Administration (FDA) recently granted approval for DBS in the treatment of obsessivecompulsive disorder. Currently, Medtronic (Minneapolis, Minn., USA) produces the only FDA-approved DBS device in the USA. In the European Union, however, St. Jude Medical has received Conformité Européenne (CE) approval for its DBS device [3], and Boston Scientific is conducting a clinical trial on its Vercise System [4], aimed at obtaining CE approval. In the USA, the efficacy of DBS for both treatment-resistant depression and for epilepsy is currently under investigation, raising the possibility that an even greater proportion of patients will soon be implanted with DBS devices [5].

Magnetic resonance imaging (MRI) of the brain is routinely used for the evaluation of patients suspected of harboring various neurological disorders, including stroke and cancer. In patients opting for DBS for the treatment of the conditions mentioned above, MRI is used for presurgical evaluation and for planning the trajectory to the target, as well as for selecting the optimal

\section{KARGER}

두 2011 S. Karger AG, Basel

Fax +41613061234 E-Mail karger@karger.ch www.karger.com www.karger.com/sfn
Aviva Abosch, $\mathrm{MD}, \mathrm{PhD}$

University of Minnesota Medical School, Department of Neurosurgery

D429 Mayo Memorial Building, 420 Delaware St., SE

MMC 96, Minneapolis, MN 55455 (USA)

Tel. +1 612626 8786, E-Mail aabosch@umn.edu 
Table 1. Manufacturer guidelines for MRI in patients with implanted DBS devices [6]
- Only 1.5-tesla horizontal-bore MRI should be used for scanning patients

- Only a transmit/receive head coil should be used

- Correct patient weight should be entered into the MRI console for calculating the head SAR correctly

- MRI parameters that allow average head SAR below or equal to $0.1 \mathrm{~W} / \mathrm{kg}$ should be used

- The gradient $\mathrm{dB} / \mathrm{dt}$ should be less than or equal to $20 \mathrm{~T} / \mathrm{s}$ location within the target. Some centers also use MRI for postoperative target confirmation, for detecting any procedural hemorrhage postoperatively and for optimizing subsequent implantable pulse generator (IPG) programming. Although after DBS implantation, these patients remain as susceptible to other neurological disorders as the general population, some hospitals and imaging centers around the world ban or restrict the use of MRI in patients with implanted DBS devices. The rationale for this stems from safety concerns over tissue heating and injury, and/or the possibility of operational disruption of the device that might result when a patient with an implanted DBS device is placed in an MR unit [6]. Imaging of medical implants under certain MRI conditions can result in local tissue heating - an observation that has been well documented (see Shellock [6] for a review). Interestingly, neither the FDA nor the International Electrotechnical Commission has issued guidelines concerning the use of MRI in patients with implanted DBS devices, leaving this task to industry, instead [7].

Industry recommendations regarding MRI safety in patients with implanted DBS devices were issued in the manufacturer's DBS device manual in January 2002. These recommendations initially stipulated the use of a specific absorption rate (SAR) value of $\leq 0.4 \mathrm{~W} / \mathrm{kg}$, and the use of a head coil for the performance of MRI scans. In 2003, Spiegel et al. [8] reported transient dystonia and ballistic movements in a 73-year-old woman with Parkinson's disease, following MRI (1.0T Expert; Siemens, Erlangen, Germany; transmit/receive head coil) for the postoperative visualization of her bilateral subthalamic nucleus DBS electrodes (model No. 3383; Medtronic Inc.). In this patient, stimulation was tested via temporary, percutaneous extension cables connected externally to a power source. The MRI scan was performed after removing the external power sources from the percutaneous extension cables, which remained partially within the head coil. The dystonic and ballistic movements ultimately resolved, but this event prompted the device manufacturer to issue a safety alert in October 2005. In November 2005, Henderson et al. [9] published a case report describing permanent neurological injury - dysarthria and right-sided hemiparesis - resulting from a lumbar MRI acquired on a patient with bilateral implanted DBS devices. This patient was an avid hunter and therefore the IPG on the left side, his shooting side, was placed in his abdomen. This case report emphasized the importance of not only following the specified guidelines, but also taking into consideration the positioning of the neurostimulator, MRI scenarios, and the scanner make and model prior to imaging a patient in whom a DBS device is implanted [9]. As a consequence of this sentinel event, several months later, independent MRI safety guidelines were published without further support from empirical data (table 1). Because of the stringency of these guidelines, some institutions follow their own precautions and policies [10], whereas others refrain entirely from obtaining any type of MRI in this patient population [11]. Tagliati et al. [11] have recently published the results of their survey of MRI safety in DBS patients, documenting that 17 out of 40 Centers of Excellence of the National Parkinson's Foundation do not perform MRIs of DBS patients, with 53\% of these centers citing industry guidelines and/or warnings as the primary reason for this policy.

Safety issues associated with obtaining an MRI scan in DBS patients include magnetic field interactions with the DBS device potentially leading to device migration, tissue injury arising from heating of the DBS device or induction of electrical currents, and functional disruption of the operational aspects of the device. Phantombased studies have been used in an attempt to address some of these issues, but it is unclear how relevant these studies are to the clinical scenario. Similar concerns about MRI safety have been raised for patients with implanted cardiovascular devices. The radiofrequency (RF)-induced electrical current that is generated in cardiac pacemakers causes heating at the lead tip, which is dependent on the configuration of device relative to the 
lead tip within the body [12]. The American Heart Association published a scientific statement in 2007 clarifying the issue of MRI safety in patients with implanted cardiovascular devices: After extensive analysis of available data, the American Heart Association determined that MRI scans can be performed in the setting of carefully screened patients with implanted and identified cardiovascular devices, who are not pacemaker dependent, under physician management and supervision, and at experienced MRI centers [13].

The purpose of this review is to stimulate research towards defining appropriate, empirically based guidelines for the use of MRI in patients with implanted DBS devices. Additionally, this review is intended to assist clinicians and biomedical researchers in making sound clinical judgments about the use of MRI in the setting of implanted DBS devices.

\section{RF and Heating}

In an MRI scanner, pulsed RF electromagnetic fields are produced using an RF head and/or body coil to obtain images. These RF pulses can induce electrical currents in patients with implanted devices, such as DBS hardware components [14]. When traveling through tissue, these induced electrical currents can produce a temperature rise causing heating, at or near the noninsulated contacts of the implanted electrode, which are situated in the brain. This temperature rise can result in thermal damage and/or tissue necrosis within the brain. The possibility of injury demands a thorough evaluation of factors that play a key role in generating potentially harmful RF heating.

\section{Phantom Studies}

Experimental investigations of MRI safety issues in the DBS population published to date have used phantoms constructed in various shapes and of various compositions (table 2). Kainz et al. [18] conducted an in vitro study to assess temperature changes at the electrode tip and surface of an ipsilaterally implanted ITREL-III IPG device (Medtronic Inc.) during 1.5-tesla (Magnetom; Siemens) and 3-tesla (Bruker) MRI scans. These investigators used a phantom consisting of a skull and a trunk form, filled with liquids of compositions simulating brain and muscle tissue [18]. These investigators reported a maximum temperature increase of $2.1{ }^{\circ} \mathrm{C}$ at the electrode tip, and speculated that this temperature rise would be lower in the clinical setting, owing to the heat dissipation that occurs as a consequence of brain blood flow. Given that reversible thermal lesions occur at $42-44^{\circ} \mathrm{C}$, and irreversible lesions occur at temperatures greater than $45^{\circ} \mathrm{C}$, these investigators concluded that the temperature increase resulting from MRI of DBS devices should not be considered harmful to patients. Other studies have used gel-filled phantoms in order to simulate the thermal convection and dielectric properties of human tissues [16]. Maximum temperature increases at the electrode tip have ranged from $0.15^{\circ} \mathrm{C}$ [14] to $25.3^{\circ} \mathrm{C}$ [16], across different phantom studies and depending on various factors and conditions of scanning (table 2). These phantom studies have provided some useful information about different variables such as SAR [16], field strength [18] and coil type, and the association between these variables and temperature rise at the DBS electrode tip in patients implanted with DBS devices. However, phantom materials fail to replicate such factors as the heat dissipation effects of human brain tissue and blood flow, and provide only an approximation of the composition of the human body. As the consequences of human head geometry, of the thermodynamic properties of human brain tissue, bone and scalp, and of thermoregulatory effects of blood flow in the brain, have not yet been replicated in phantom studies, the validity of extrapolating phantom study results to human subjects is uncertain.

\section{Factors Influencing RF Heat Generation and Measurement}

\section{Specific Absorption Rate}

As described above, the current induced by pulsed RF electromagnetic fields is the major cause of power generation, resulting in heat deposition in tissue. This power deposited in imaged tissue during an MRI scan is quantified by calculating the SAR, expressed in units of watts per kilogram. The SAR is defined as a mass-normalized rate at which RF power is coupled to biological tissue - in other words, the amount of RF power that is absorbed per unit mass of an object [21].

The SAR is calculated differently for different MRI manufacturers - and even varies for different systems produced by the same manufacturer. Published studies in this field have thus far used different MR systems with different transmit/receive head or body coils (table 2), leading to difficulty in extrapolating results to other situations. In 2004, Baker et al. [7] compared the MRI-related 
Table 2. Characteristics of published studies aimed at assessing patient safety during MRI of implanted DBS devices

\begin{tabular}{|c|c|c|c|c|c|c|}
\hline Study & Phantom type & $\begin{array}{l}\text { Clinical } \\
\text { study }\end{array}$ & $\begin{array}{l}\text { MRI field strength } \\
\text { and manufacturer }\end{array}$ & Coil type specified & $\begin{array}{l}\text { Temperature } \\
\text { assessment }\end{array}$ & IPG model \\
\hline $\begin{array}{l}\text { Gleason } \\
\text { et al. [15] }\end{array}$ & Water-filled phantom & NA & $\begin{array}{l}\text { 1.5-tesla General Electric } \\
\text { Signa IIs; } 0.35 \text {-tesla } \\
\text { Diasonics MT/S }\end{array}$ & Head and body coil & $\begin{array}{l}\text { Fluoroptic } \\
\text { sensor }\end{array}$ & $\begin{array}{l}\text { Itrel I } \\
\text { (Medtronic Inc.) }\end{array}$ \\
\hline $\begin{array}{l}\text { Tronnier } \\
\text { et al. [14] }\end{array}$ & Various salt solutions & $\begin{array}{l}\text { Patient } \\
\text { interviews }\end{array}$ & $\begin{array}{l}\text { 0.2-tesla Siemens Magnetom } \\
\text { Open; } 1.5 \text {-tesla Picker Edge; } \\
0.25 \text {-tesla Picker Outlook } \\
\text { (in vivo) }\end{array}$ & $\begin{array}{l}\text { Transmit/receive } \\
\text { coils }\end{array}$ & $\begin{array}{l}\text { Infrared } \\
\text { camera }\end{array}$ & $\begin{array}{l}\text { Itrel II, Itrel III } \\
\text { (Medtronic Inc.) }\end{array}$ \\
\hline $\begin{array}{l}\text { Rezai } \\
\text { et al. [16] } \\
\text { and Baker } \\
\text { et al. [17] }\end{array}$ & $\begin{array}{l}\text { Human head and } \\
\text { torso-shaped semisolid } \\
\text { gel-filled phantom }\end{array}$ & NA & $\begin{array}{l}\text { 1.5-tesla Siemens Vision } \\
\text { [Rezai et al. and Baker et al.]; } \\
\text { 1.5-tesla Siemens Symphony } \\
\text { [Baker et al.] }\end{array}$ & $\begin{array}{l}\text { Transmit/receive } \\
\text { head and body coil }\end{array}$ & $\begin{array}{l}\text { Fluoroptic } \\
\text { thermometry }\end{array}$ & $\begin{array}{l}\text { Soletra Model } 7426 \\
\text { (Medtronic Inc.) }\end{array}$ \\
\hline $\begin{array}{l}\text { Kainz } \\
\text { et al. [18] }\end{array}$ & $\begin{array}{l}\text { Skull and torso-shaped } \\
\text { phantom filled with } \\
\text { brain and muscle-like } \\
\text { liquids }\end{array}$ & NA & $\begin{array}{l}\text { 1.5-tesla Siemens Magnetom; } \\
\text { 3.0-tesla Bruker }\end{array}$ & NS & Fiberoptic & $\begin{array}{l}\text { Itrel III } \\
\text { (Medtronic Inc.) }\end{array}$ \\
\hline $\begin{array}{l}\text { Kovacs } \\
\text { et al. [19] }\end{array}$ & NA & $\begin{array}{l}\text { Retrospec- } \\
\text { tive review }\end{array}$ & $\begin{array}{l}\text { 1.0-tesla Siemens Magnetom } \\
\text { Harmony }\end{array}$ & $\begin{array}{l}\text { Transmit/receive } \\
\text { head coil }\end{array}$ & NS & $\begin{array}{l}\text { Soletra, Kinetra } \\
\text { (Medtronic Inc.) }\end{array}$ \\
\hline $\begin{array}{l}\text { Larson } \\
\text { et al. [20] }\end{array}$ & NA & $\begin{array}{l}\text { Retrospec- } \\
\text { tive review }\end{array}$ & $\begin{array}{l}\text { 1.5-tesla Siemens Magnetom } \\
\text { Vision; } 1.5 \text {-tesla Siemens } \\
\text { Magnetom Symphony; } \\
\text { 1.5-tesla Philips Intera; } \\
\text { 1.5-tesla General Electric } \\
\text { Horizon }\end{array}$ & $\begin{array}{l}\text { Combination of } \\
\text { body transmit/head } \\
\text { receive and head } \\
\text { transmit/receive } \\
\text { coils }\end{array}$ & NS & $\begin{array}{l}\text { Itrel II, Soletra, } \\
\text { Kinetra (Medtronic } \\
\text { Inc.); ANS Libra }\end{array}$ \\
\hline
\end{tabular}

NA = Not applicable (not performed); NS = not specified.

heating of a DBS implant (per unit whole-body-averaged SAR) exposed to short- and long-bore configurations of the magnet in the same Siemens (Malvern, Pa., USA) 1.5-tesla MR system, and found that the amount of heating per unit change in the calculated whole-body-averaged SAR was 90 times higher when using a transmit/ receive body coil on the 1.5-tesla MRI short-bore system versus the long-bore system. These authors suggested, therefore, that the use of the calculated whole-body-averaged SAR (MRI scanner-derived) is not a reliable means of calculating RF power irradiation across different MR systems from the same manufacturer, let alone different manufacturers. The authors did note that their findings supported a linear relationship between SAR and tissue heating, within a given MR system. However, they cautioned that differences in the method of SAR calculation across different MR manufacturers prevent the use of SAR as a metric for determining MR safety. Studies such as this one support the need to conduct systematic and thorough investigations into the primary variables used for calculating the SAR value - such as body and head weight, estimated RF power absorption by tissues, and coil type - and underscore the importance of adopting a standardized, universally accepted method of measuring RF deposition in tissue.

\section{Temperature Assessment Techniques}

The accurate assessment of temperature changes at or near the tip of an implanted electrode and surrounding the IPG is critical for assessing patient safety during MRI. Furthermore, the specific method by which temperature is measured is an important factor in determining the validity of in vitro and in vivo studies aimed at recording RF-induced heating during MRI in DBS studies. Tronnier et al. [14] measured temperature in a saline-filled phantom via a thermal image-processing system connected to an infrared camera. The use of an infrared camera enables the remote measurement 
of temperature changes at the surface of the electrode tip - although this is disputed [18] - and was chosen by these investigators so as to avoid distortion that might be induced by proximity of the DBS electrodes to an electrical thermometer. These authors noted a maximum rise of $0.15^{\circ} \mathrm{C}$ at the lead tip and at the IPG surface, which was also the limit of temperature resolution of the infrared camera used for the study. Additionally, the saline solution in which the electrode was placed might have allowed for redistribution of heat generated during scanning, which could lead to an underestimation of the actual temperature rise.

Other investigators have used small probes equipped with fluoroptic temperature sensors [15-18], which have a resolution close to $0.1{ }^{\circ} \mathrm{C}$ and are in direct contact with the tissue being studied. These fluoroptic probes therefore measure temperature changes directly in the surrounding tissue. Fluoroptic probes use the decay time of emitted light of a fluorescent material, such as phosphor, as a surrogate to provide precise information about rapid temperature changes relative to time (0.05-2 s) [22]. Although possessing greater temporal and spatial resolution than the infrared camera approach, the use of fluoroptic probes to measure temperature changes is not without problems. For instance, fluoroptic probes are more fragile, frequently need to be recalibrated and are designed for room temperature environments, unlike the high temperature and pressure within the MRI [22].

\section{DBS Component Configuration}

Heating in brain tissue surrounding the DBS electrode is produced by electric currents induced in the electrodes by RF pulses. These currents can be induced by changes in electromagnetic fields through a wire loop. The change in the electromagnetic fields over a given time is directly proportional to the current that is induced in the wire. Since the frequency (field strength) of the MRI scanner is fixed, the only other factor that may control the current induced and hence the heating at the electrode tip is the amount of electromagnetic flux, which is directly proportional to the surface area of the wire loop [23]. Therefore, electromagnetic field flux changes caused by changing the location of the hardware wire loop - from subcutaneous scalp, to neck, or chest - and the area of the loop, are the two primary surgically modifiable factors involved in producing electric currents and thus heating in DBS electrodes.

Electromagnetic fields generated in a head coil become weaker as the distance from the head coil increases. Therefore, only hardware loops underlying the scalp con- tribute significantly to potential brain heating induced during MRI using a head transmit/receive coil. In the case of a body coil, because both the head and trunk of the DBS patient would lie in the magnetic field, every loop (in the subcutaneous scalp, neck or chest region) would serve as a source of potential heating around the implanted DBS device. Neurosurgical techniques, like creating smaller hardware loops or even reducing the number of loops, are thus important ways to minimize the risk of clinically significant heating. Currently, extensions come in 3 lengths $-51 \mathrm{~cm}$, which is used for the majority of patients, $95 \mathrm{~cm}$, which is used for abdominal subcutaneous IPG placements, and $66 \mathrm{~cm}$ (model No. 7482A; Medtronic Inc.). These phenomena underscore the importance of having extension cables that are tailored to the height of the specific patient, which would eliminate the necessity to coil up redundant lengths of extension cable, and thus the generation of additional heating.

FDA-approved DBS systems currently consist of a 40$\mathrm{cm}$ electrode, generally a 51-cm extension cable (assuming IPG placement in the infraclavicular region) and an IPG. The electrode is implanted in the brain using stereotactic technique, via a burr hole drilled through the skull. The extracranial portion of the electrode is then coiled underneath the scalp, connected to the extension cable which is tunneled underneath the skin to the upper chest, where it is connected to an IPG. The IPG consists of a battery and programmable hardware. Typically, the excess extracranial electrode lead is looped around the burr hole or in an adjacent subgaleal pocket, and the excess extension cable is coiled around the perimeter of the IPG in the chest (fig. 1, configuration A; 'typical configuration'). Some surgeons prefer to coil the excess extension cable and place it underneath the IPG to prevent possible damage during subsequent IPG replacement surgeries, typically performed every 3-5 years for depletion of battery life.

In an effort to determine worst-case configuration and SAR scenarios and to acquire data regarding typical clinical component configurations, Rezai et al. [16] tested various DBS positions using a Plexiglas phantom of a human head and torso, filled with a semisolid gel. A 1.5-tesla MRI system (Siemens) was used for imaging, with either a transmit/receive head or body coil, using various SAR values. With respect to coil type, the authors noted that whole-body-averaged and local SAR were significantly lower using the head coil as opposed to the body coil. The DBS component positioning scenarios tested included a configuration in which the extracranial portion 
Fig. 1. Configurations of the electrode implanted, its extracranial portion and the IPG.

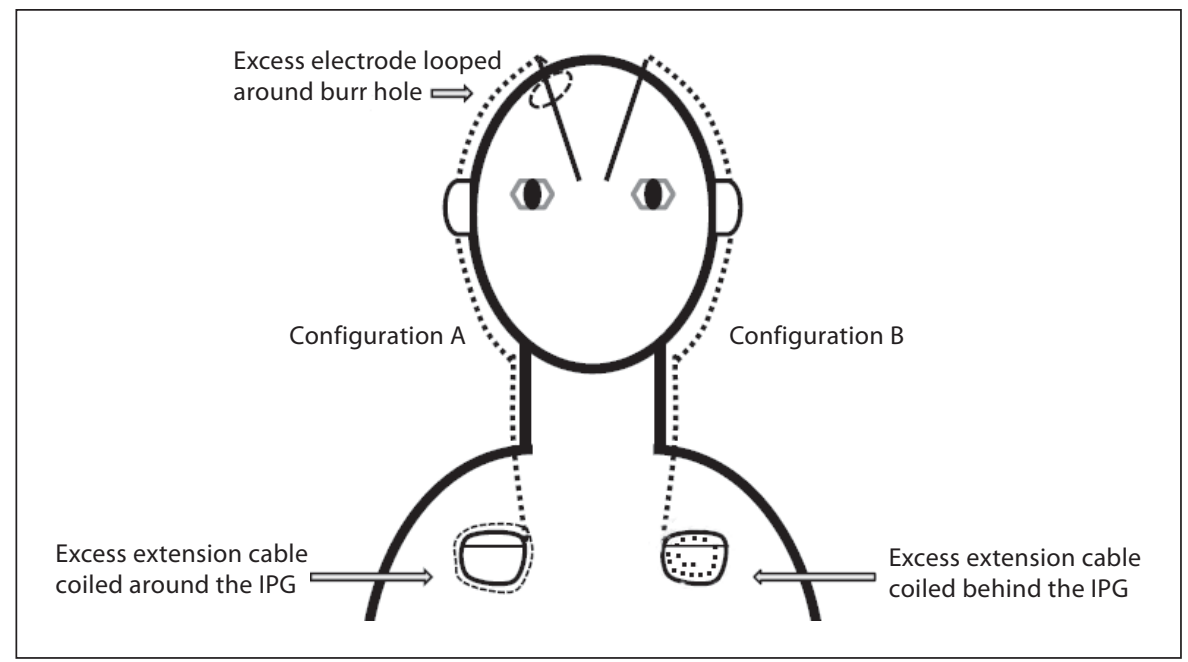

Table 3. Recommended guidelines for the use of MRI in patients implanted with bilateral DBS systems, by Rezai et al. [10]

1 IPGs should be placed in infraclavicular subcutaneous pockets, separated by a distance of approximately $30 \mathrm{~cm}$, if IPGs are bilateral. Extracranial DBS electrodes to be placed as small loops (approx. $2.5 \mathrm{~cm}$ in diameter) in an axial orientation near the burr hole. Excess length of extension cables should be wrapped around the perimeter of the IPGs. Do not bend, kink or stretch extension cables

2 Interrogate DBS system before MRI scan to ensure proper operation of all components and absence of broken electrodes, extension cables and IPGs

3 Amplitude and output of each IPG should be set to 'off mode and $0 \mathrm{~V}$

4 Use only 1.5-tesla MRI system, as the safety of other magnetic field strengths in the DBS population is unknown

5 Whole-body-averaged SAR should not exceed $0.9 \mathrm{~W} / \mathrm{kg}$ for transmit/receive body RF coil

6 Whole-body-averaged SAR should not exceed $0.1 \mathrm{~W} / \mathrm{kg}$ for transmit/receive head RF coil

7 MRI should be performed using standard techniques, with lowest possible SAR levels, as indicated above

8 Prior to MRI, patients should be instructed to report any unusual sensations that may occur during the MRI scan

9 Patients should be monitored throughout the MRI scan, using visual and/or verbal means

10 DBS system should be evaluated after MRI scan to verify that it is functional

11 DBS system should be reprogrammed following MRI scan to prescan stimulation parameters of the electrode was not coiled, but was extended down towards the chest, with the extra extension cable coiled around the perimeter of the IPG (fig. 1, configuration B; 'worst-case' scenario). In a setting of bilateral IPGs, the highest temperature rise for configuration $A$, using a transmit/receive body coil with a whole-body SAR value of $3.90 \mathrm{~W} / \mathrm{kg}$, was measured as $6.1^{\circ} \mathrm{C}$. In contrast, when the extra electrode length was extended down towards the chest instead of being looped around the burr hole, and the extra extension cable was looped around the perimeter of the IPG (configuration $B$ ), a maximum temperature rise of $25.3^{\circ} \mathrm{C}$ was measured, with a whole-body SAR value of $3.9 \mathrm{~W} / \mathrm{kg}$, using a transmit $/$ receive body coil. The least amount of heating at the electrode was associated with component configuration $\mathrm{A}$, the use of a head coil, and a whole-body SAR value of $0.07 \mathrm{~W} / \mathrm{kg}$. Based on this careful in vitro study, Rezai et al. [10] concluded that SAR value, coil type and component configuration were all critical factors in determining the extent of MRI-related heating in the setting of a DBS implant. These investigators therefore recommended that for patients undergoing DBS implantation, the extra DBS electrode length should be placed in an axial orientation near the burr hole, in the form of small loops (roughly $2.5 \mathrm{~cm}$ in diameter), and that the excess length of extension cable should be wrapped around the IPG perimeter without bending, kinking or stretching it (table 3). Although quantitative measurements were not provided, Rezai et al. [10] noted that MRI-related heating was further reduced by the avoidance of loops in the excess electrode and extension cable. 


\section{In vivo Studies}

Only 3 studies to date $[14,19,20]$ have described clinical experience with MRI of patients bearing implanted DBS systems. In 1999, Tronnier et al. [14] interviewed 20 patients with implanted DBS devices (12 patients with bilateral DBS electrodes) immediately after MRI scanning (0.25-tesla Outlook MRI scanner, Picker International). Patients were asked about any symptoms they might have experienced during MRI - e.g. shock-like sensations, paresthesias or a sense of heating. Of note, no adverse events were noted in or by patients with implanted DBS electrodes (model 3387/88/89), irrespective of whether or not the DBS electrode was already connected to an IPG. Interestingly, 2 patients in this study, both with implanted spinal cord stimulators (not DBS), underwent scanning while the IPG was turned 'on' and connected to implanted spinal-cord-stimulating electrodes. Each of these patients experienced brief, painful dysesthesias during imaging, forcing the investigators to modify their protocol mid study and begin setting the IPG to $0 \mathrm{~V}$ in addition to turning the IPG 'off'. Although the authors do note the use of transmit/receive coils for scanning, further details about whether a body or head coil was used were not provided. This study was the first published assessment of patient-reported effects of MRI-induced heating in the setting of implanted DBS devices.

Kovacs et al. [19] and Larson et al. [20] have recently described their clinical experience with imaging DBSimplanted patients using 1.0- and 1.5-tesla MR scanners, respectively. Both studies were retrospective in nature, and the authors used different MR manufacturers for imaging (Siemens; Philips; General Electric). To minimize the possibility of any RF-related adverse events while imaging 34 DBS patients between 2 weeks and 1 year after DBS implantation, Kovacs et al. [19] followed industry guidelines by lowering the gradient switching to less than $20 \mathrm{~T} / \mathrm{s}$ and using a lower SAR value of $<0.1 \mathrm{~W} / \mathrm{kg}$. During their 4 years of imaging DBS patients under these conditions, no adverse events relating to the MRI scanning were noted.

In 2008, Larson et al. [20] published their 7-year experience with imaging 746 implanted DBS leads. These authors reported that they routinely turn the IPG 'off' and set the amplitude to $0 \mathrm{~V}$ before scanning DBS-implanted patients. These authors also described scanning DBS-implanted patients occasionally with the IPG turned to 'off' but the amplitude set to existing patient-specific therapeutic levels. Some patients among this group were noted to have transient paresthesias, thought to be due to the
IPG rapidly cycling between 'on' and 'off' during scanning. No long-term, patient-specific complications or damage to the DBS hardware were noted in any of these patients. Larson et al. [20] emphasized that both $\mathrm{T}_{2^{-}}$ weighted fast spin echo and inversion recovery fast spin echo imaging sequences - sequences which provide higher resolution for analysis of postoperative electrode placement and for ruling out complications - result in higher SAR values than the existing industry guideline of SAR $<0.1 \mathrm{~W} / \mathrm{kg}$. These authors concluded that their ongoing practice of not abiding by the industry guideline of SAR $<0.1 \mathrm{~W} / \mathrm{kg}$ in all pulse sequences was justified based on their record of safely scanning many DBS patients using different scanning parameters on multiple hardware and software configurations without a single resulting adverse event.

In 2010, Chhabra et al. [24] published a retrospective study of 64 patients who had undergone staged, bilateral DBS surgery. Three separate MR studies were obtained in each patient: (1) within $24 \mathrm{~h}$ of the first DBS electrode implantation, (2) immediately prior to the contralateral DBS electrode placement and (3) within $24 \mathrm{~h}$ of the contralateral DBS electrode implantation. Imaging was performed on a 1.5-tesla General Electric (Sigma), Philips (Achieva) or Siemens (Symphony) scanner, with a SAR value of $0.1-0.8 \mathrm{~W} / \mathrm{kg}$ using a receive-only head coil. Patients were monitored for the onset of new neurological deficits related to MRI. Although the incidence of new neurological deficits from surgery was $16.1 \%$, no neurological deficits related to the MRI were identified in any of these patients, lending further support to the fact that MRI, under certain conditions, can be performed safely in patients with implanted DBS devices.

Recently, Ullman et al. [25] published their results of 3-tesla MRI on 4 postmortem brains that had prior DBS lead implantation. There were bilateral DBS leads implanted in 3 of the postmortem brains and a unilateral DBS lead in 1. Each brain was removed from the skull after detaching the DBS electrode from the extension cable. Histopathological analysis of the electrode-implanted brains following 3-tesla imaging $12 \mathrm{~h}$ in duration demonstrated no evidence of tissue damage.

\section{Existing Recommendations}

Since the introduction of DBS, several groups have proposed safety guidelines regarding the issue of MRI for DBS patients. In 1992, for instance, Gleason et al. [15] suggested that a patient implanted with an Itrel I IPG 
(Medtronic, model No. 7421) could be scanned if the IPG voltage was adjusted to $0 \mathrm{~V}$ and the distance from the isocenter of the magnet was greater than $40 \mathrm{~cm}$.

Based on their phantom studies in 2002, Rezai et al. [16] recommended specific guidelines for the use of MRI in patients implanted with DBS (table 3). These recommendations were intended for bilaterally implanted DBS electrodes (model 3387 or 3389), each connected to an IPG (Soletra Model 7426) by a quadripolar extension cable (model 7495). It is not clear how applicable these guidelines are to the newly released DBS electrode model 3391 (for the treatment of obsessive-compulsive disorder) or to rechargeable IPGs.

Finally, safety considerations have prompted industry to issue a number of stringent guidelines (table 1) regarding the use of MRI in patients with implanted DBS systems, and to issue periodic warnings to patients regarding the risks of MRI in the setting of an implanted DBS device.

Given the variability in SAR calculations between MRI manufacturers, and even between different field strength MR scanners of the same manufacturer, it is worth noting that the techniques proposed so far by various groups to reduce MRI-related heating in DBS-implanted patients should be restricted to the specific MR scanners and DBS devices used in the test conditions described - with the understanding that phantom studies do not necessarily replicate the in vivo situation.

\section{Discussion}

Review of existing in vitro and in vivo studies of MRI performed in the setting of implanted DBS devices indicates that more data are required to develop rational guidelines about the parameters of MRI in this patient population. MRI is a powerful diagnostic tool and crucial for the clinical evaluation of a number of acute and chronic disorders that affect the central nervous system. It is therefore essential to be able to use MRI in the increasing proportion of patients with implanted DBS devices. Safety issues such as magnetic field interactions with the DBS device leading to component migration, induced electrical currents and tissue heating are of great concern when considering the use of MRI in patients with implanted DBS systems. In some cases, these issues can be avoided by the use of alternate neuroimaging modalities such as computerized tomography and transcranial Doppler ultrasonography, but there are clinical scenarios in which MRI is mandatory. Chief among all safe- ty concerns is the possibility of causing a clinically significant rise in temperature as a consequence of current induction due to the electromagnetic fields generated by the MR system. Such a temperature rise has the potential to cause thermal injury to brain parenchyma or frank tissue necrosis, and may result in transient or permanent neurological deficits, such as paresis, paralysis, dystonia, coma or even death [26]. The current induction produced by electromagnetic field RF pulses is a function of multiple factors, including the number, type, frequency, repetition rate and duration time of the RF pulses, the transmission RF coil type, and the geometry and composition of the tissue being imaged. Additionally, since at increasing magnetic field strengths, the image resolution of deep brain nuclei - including the various targets for DBS surgery - improves dramatically, there is potential for improved MRI-based targeting of DBS electrodes, leading to greater surgical accuracy and therefore better postoperative efficacy. Analysis of safety issues at high magnetic field strengths, for example $7 \mathrm{~T}$, has not yet been published. It is therefore imperative to devise a suitable thermal model that will accurately determine temperature changes and the association of these temperature changes with all of the variables mentioned above, enabling researchers to answer critical questions regarding the safety of DBS patients in various MR systems.

A valid model system for the analysis of MRI-induced heating around implanted DBS devices must take into account the following points:

- Phantom models intended to simulate human tissue lack the considerable heat dissipation effects (since blood can cool as well as heat tissue) that result from cerebral perfusion and thus produce temperature changes that are not necessarily applicable to the in vivo situation [17]. Mammals possess mechanisms that can result in extensive alterations in skin perfusion [27], enabling thermoregulation. RF-induced temperature response and thermal diffusion vary with time-varying changes in skin perfusion - which, in turn, are associated with the temperature of the environment and also with the time of day. For these reasons, animal models that are comparable to humans with respect to thermal mass, surface area, head geometry, and thermoregulatory mechanisms are superior to phantom models. A perfused human cadaver model can also be used to replicate RF-induced temperature rises in the setting of implanted DBS devices. 
- Because elevated temperatures can cause thermal injury to cells, it is important to determine the correlation between in vivo temperature changes and SAR in order to ensure safety in MR systems of different field strengths [28].

- Furthermore, we advocate the use of fluoroptic temperature probes located at the electrode tip and in surrounding tissues, in order to provide accurate information about RF-induced temperature changes in a comprehensive survey of DBS component configurations and MR manufacturers.

The various studies described in this review are not comparable to one another, owing to the use of different phantom materials, electrode configurations, positions of the phantom in the MRI, RF coil types, pulse protocols, and the existence of different static magnetic fields of the various MR systems [18]. This variability prevents the application of the data generated to other MR setups and suggests that MR system manufacturers should be encouraged to adopt a uniform method of measuring RF deposition in tissues, and that the medical device industry should be encouraged to develop MRI-compatible DBS devices. In the meantime, new, comprehensive studies are needed that take into account factors related to the
MR system (e.g. electromagnetic field strength, SAR value, number and type of sequences), RF coil (type, size), DBS electrodes (unilateral vs. bilateral), extension cable (length, configuration of coils), IPG (model number, position with respect to RF coil and loops of extension cable) and patient characteristics (presence of other implanted devices). Such investigations should be aimed at helping to formulate data-driven, international guidelines for MRI of patients with implanted DBS devices. The data generated will assist healthcare providers and biomedical researchers in avoiding adverse events $[8,9]$, and will serve as a scaffolding for the effort to design new implantable devices compatible with the increasing number of high-field MR systems worldwide.

\section{Acknowledgments}

The authors wish to thank Lee Sternberg, University of Minnesota Medical Center-Fairview, and Neeraj Gaur, Department of Electrical Engineering, University of Minnesota, for their helpful comments. This research was supported by a Career Development Award from the National Center for Research Resources to A. Abosch (5K12-RR03358-03).

\section{References}

1 Krack P, Batir A, Van Blercom N, et al: Fiveyear follow-up of bilateral stimulation of the subthalamic nucleus in advanced Parkinson's disease. N Engl J Med 2003;349:19251934.

-2 Tir M, Devos D, Blond S, et al: Exhaustive, one-year follow-up of subthalamic nucleus deep brain stimulation in a large, single-center cohort of parkinsonian patients. Neurosurgery 2007;61:297-304.

3 St Jude Medical announces European CE mark approval for Libra deep brain stimulation systems for Parkinson's disease. St Jude Medical News Release January 26, 2009.

4 Boston Scientific begins patient enrollment in clinical trial assessing deep brain stimulation for Parkinson's disease - company implants its first deep brain stimulation device designed to treat Parkinson's. Boston Scientific News Release November 9, 2010.

$\checkmark 5$ Roark C, Whicher S, Abosch A: Reversible neurological symptoms caused by diathermy in a patient with deep brain stimulators: case report. Neurosurgery 2008;62:E256.

6 Shellock FG: Magnetic resonance safety update 2002: implants and devices. J Magn Reson Imaging 2002;16:485-496.
7 Baker KB, Tkach JA, Nyenhuis JA, et al: Evaluation of specific absorption rate as a dosimeter of MRI-related implant heating. J Magn Reson Imaging 2004;20:315-320.

8 Spiegel J, Fuss G, Backens M, et al: Transient dystonia following magnetic resonance imaging in a patient with deep brain stimulation electrodes for the treatment of Parkinson disease: case report. J Neurosurg 2003; 99:772-774.

$\checkmark 9$ Henderson JM, Tkach J, Phillips M, Baker K, Shellock FG, Rezai AR: Permanent neurological deficit related to magnetic resonance imaging in a patient with implanted deep brain stimulation electrodes for Parkinson's disease: case report. Neurosurgery 2005; 57:E1063.

10 Rezai AR, Baker KB, Tkach JA, et al: Is magnetic resonance imaging safe for patients with neurostimulation systems used for deep brain stimulation? Neurosurgery 2005;57: 1056-1062.

11 Tagliati M, Jankovic J, Pagan F, Susatia F, Isaias IU, Okun MS: Safety of MRI in patients with implanted deep brain stimulation devices. Neuroimage 2009;47(suppl 2):T53-T57.
12 Nordbeck P, Weiss I, Ehses P, et al: Measuring RF-induced currents inside implants: impact of device configuration on MRI safety of cardiac pacemaker leads. Magn Reson Med 2009;61:570-578.

13 Levine GN, Gomes AS, Arai AE, et al: Safety of magnetic resonance imaging in patients with cardiovascular devices: an American Heart Association scientific statement from the Committee on Diagnostic and Interventional Cardiac Catheterization, Council on Clinical Cardiology, and the Council on Cardiovascular Radiology and Intervention: endorsed by the American College of Cardiology Foundation, the North American Society for Cardiac Imaging, and the Society for Cardiovascular Magnetic Resonance. Circulation 2007;116:2878-2891.

14 Tronnier VM, Staubert A, Hahnel S, SaremAslani A: Magnetic resonance imaging with implanted neurostimulators: an in vitro and in vivo study. Neurosurgery 1999;44:118-125. 15 Gleason CA, Kaula NF, Hricak H, Schmidt RA, Tanagho EA: The effect of magnetic resonance imagers on implanted neurostimulators. Pacing Clin Electrophysiol 1992;15:8194. 
-16 Rezai AR, Finelli D, Nyenhuis JA et al: Neurostimulation systems for deep brain stimulation: in vitro evaluation of magnetic resonance imaging-related heating at 1.5 tesla. J Magn Reson Imaging 2002;15:241-250.

- 17 Baker KB, Tkach JA, Phillips MD, Rezai AR: Variability in RF-induced heating of a deep brain stimulation implant across MR systems. J Magn Reson Imaging 2006;24:12361242.

-18 Kainz W, Neubauer G, Uberbacher R, Alesch F, Chan DD: Temperature measurement on neurological pulse generators during $\mathrm{MR}$ scans. Biomed Eng Online 2002;1:2.

19 Kovacs N, Nagy F, Kover F, et al: Implanted deep brain stimulator and 1.0-tesla magnetic resonance imaging. J Magn Reson Imaging 2006;24:1409-1412.
20 Larson PS, Richardson RM, Starr PA, Martin AJ: Magnetic resonance imaging of implanted deep brain stimulators: experience in a large series. Stereotact Funct Neurosurg 2008;86:92-100.

21 Jin J: Electromagnetic Analysis and Design in Magnetic Resonance Imaging. Boca Raton, CRC Press, 1999.

22 Tang J: Fiber-Optic Measurement Systems: Microwave and Radio Frequency Heating Applications. Encyclopedia of Agricultural, Food and Biological Engineering. In press

23 Griffiths DJ: Introduction to Electrodynamics, ed 3. Upper Saddle River, Prentice Hall, 1999.

24 Chhabra V, Sung E, Mewes K, Bakay RA, Abosch A, Gross RE: Safety of magnetic resonance imaging of deep brain stimulator systems: a serial imaging and clinical retrospective study. J Neurosurg 2010;112:497-502.
25 Ullman M, Vedam-Mai V, Krock N, et al: A pilot study of human brain tissue post-magnetic resonance imaging: information from the National Deep Brain Stimulation Brain Tissue Network (DBS-BTN). Neuroimage 2011;54S1:S233-S237.

26 Rezai AR, Phillips M, Baker KB, et al: Neurostimulation system used for deep brain stimulation (DBS): MR safety issues and implications of failing to follow safety recommendations. Invest Radiol 2004;39:300-303.

27 Christensen P, Hjarbaek J, Jensen B, Gronlund J: Measurement of transcutaneous $\mathrm{PO}_{2}$, $\mathrm{PCO}_{2}$ and skin blood flow at different probe temperatures using mass spectrometry. Acta Anaesthesiol Scand 1991;35:631-634.

28 Shrivastava D, Hanson T, Schlentz R, et al: Radiofrequency heating at 9.4 T: in vivo temperature measurement results in swine. Magn Reson Med 2008;59:73-78. 